\title{
Hizbul Wathan Bagi Pendidikan Kemandirian Tingkat Sekolah Dasar
}

\author{
Wiranthi Prastomo ${ }^{1}$, Muhiyatul Huliyah ${ }^{2}$, M. Nasrudin ${ }^{3}$, Intan Kusumawati ${ }^{4}$, Nuryati ${ }^{5 *}$, \\ A.N. Aribowo ${ }^{6}$ \\ ${ }^{13456}$ Universitas Cokroaminoto Yogyakarta, ${ }^{2}$ Sultan Maulana Hasanuddin Banten \\ Penulis Koresponden, email: nuryatiucy93@gmail.com
}

\begin{abstract}
Abstrak
Penelitian ini bertujuan untuk mendeskripsikan pendidikan kemandirian melalui kegiatan HW tingkat athfal di salah satu SD Muhammadiyah di Yogyakarta. Dalam Penanaman karakter mandiri tentu khas dari Pramuka apabila merujuk bahwa keduanya memiliki perbedaan dan persamaan dalam kepanduan. Relasi Pembina dan perserta siaga ibarat relasi pendidik dan peserta didik yang merujuk pada Quran sebagai pedoman pokok Islam sebagai fokus utama dalam HW. Penelitian lapangan berparadigma kualitatif ini dengan cara mengamati secara langsung pelaksanaan ekstrakurikuler $\mathrm{HW}$ tingkat Athfal di Sekolah Dasar Muhammadiyah Serut kabupaten Bantul. Dengan materi dan metode pelaksanaan kegiatan yang ada Pendidikan kemandirian dalam kegiatan Ekstrakurikuler Hizbul Wathan di SD Muhammadiyah Serut telah selaras dengan UU No. 20 tahun 2003 Tentang Sistem Pendidikan Nasional bahwa fungsi pendidikan untuk mengembangkan kekuatan spiritual keagamaan, pengendalian diri, kepribadian, kecerdasan, akhlak mulia, serta keterampilan yang diperlukan peserta didik, masyarakat, bangsa dan negara.
\end{abstract}

Kata kunci: pendidikan kemandirian, Hizbul Wathan (HW), ekstrakurikuler, sekolah dasar

\begin{abstract}
This study aims to describe self-reliance education through $\mathrm{HW}$ activities at the athfal level in one of Muhammadiyah elementary schools in Yogyakarta. In planting an independent character, it is certainly typical of Scouts when it refers that both of them have differences and similarities in scouting. The relationship between the supervisor and the standby participant is like the relationship between educators and students who refer to the Quran as the main guideline for Islam as the main focus in HW. This qualitative paradigm field research was by directly observing the implementation of $\mathrm{HW}$ extracurricular activities at the Athfal level at the Muhammadiyah Primary School in Serut, Bantul district. With the materials and methods of implementing existing activities, the independence education in Hizbul Wathan Extracurricular activities at SD Muhammadiyah Serut is in line with Law no. 20 of 2003 concerning the National Education System that the function of education is to develop religious spiritual strength, self-control, personality, intelligence, noble character, and skills needed by students, society, nation and state.
\end{abstract}

This is an open access article under the CC-BY-SA license @) (1) (2) 
Keywords: self-reliance education, Hizbul Wathan (HW), Extracurricular, elementary school

\section{Pendahuluan}

Pendidikan kemandirian Indonesia tidak bisa melepaskan dari tujuan pendidikan Negara Republik Indonesia yang secara aktif mengembangkan potensi diri siswa untuk, "memiliki kekuatan spiritual keagamaan, pengendalian diri, kepribadian, kecerdasan, akhlak mulia, serta keterampilan yang diperlukan dirinya, masyarakat, bangsa dan negara" (RI 2003). Di tingkat pendidikan dasar, dijabarkan lebih lanjut dalam Peraturan Pemerintah Nomor 17 Tahun 2010 tentang Pengelolaan Penyelenggaraan Pendidikan pasal 67 ayat (3). Pendidikan dasar bertujuan:

"Membangun landasan bagi berkembangnya potensi peserta didik agar menjadi manusia yang (a) beriman dan bertakwa kepada Tuhan Yang Maha Esa; (b) berilmu, cakap, kritis, kreatif, dan inovatif; (c) sehat, mandiri, dan percaya diri; (d) toleran, peka sosial, demokratis, dan bertanggungjawab"(RI 2010)

Kemandirian itu dibentuk melalui sistem among yang menjadi landasan pendidikan nasional dalam relasi pendidik dan terdidik. Sistem berjiwa kekeluargaan dengan sendi kodrat alam dan kemerdekaan (Junaedi 2018). Kodrat alam merupakan perwujudan iman kepada Tuhan dimana manusia sebagai makhluk setara dengan makhluk yang lain yang harus tunduk kepada ketentuan alamiah dan menyeleraskan kehidupan dengan kodrat alam sehingga menjadi etos demikian budaya universal. Adapun kemerdekaan menjadi syarat mutlak dalam pergerakan dinamis dari kekuatan lahir-batin terdidik untuk menjadi pribadi kuat dalam pikiran dan tindakan. Pendidikan demikian menjadi peserta didik menjadi pusat pembelajaran utama (Sarumaha 2016)

Junaedi (2018) melanjutkan penjelasannya dengan menguatkan dari pemikiran-pemikiran tokoh-tokoh pendidikan nasional dalam menjelaskan sistem among. Implementasinya selalu disertai dengan sikap cinta kasih, saling menghormati, menghargai, demokratis, tidak berpihak kepada aliran dan golongan tertentu. Subyek utama adalah anak terdidik dimana pamong 
berperan sebagai pembimbing. Kemerdekaan lahir dan batin hingga menjadi manusia yang bermanfaat bagi diri sendiri dan lingkungannya adalah tujuan pembimingan dengan penggalian potensi alamiah anak tumbuh kembang secara leluasa.

Pengembangan kemandirian di sekolah dasar pun tidak terbatas pada kegiatan dalam kelas yang termasuk dalam intra kurikuler. Kegiatan di luar kelas yang berjenis ekstra kurikuler juga menjadi pendukungnya. Kegiatan terakhir adalah, "Kegiatan non-pelajaran formal yang dilakukan peserta didik sekolah, diluar program yang tertulis di dalam kurikulum, seperti latihan kepemimpinan dan pembinaan siswa." (Depdiknas RI 2008:360). Ekstrakurikuler termasuk dalam kegiatan pembinaan kesiswaan, yaitu "kegiatan pendidikan di luar mata pelajaran dan pelayanan konseling untuk membantu pengembangan peserta didik sesuai dengan kebutuhan, potensi, bakat, dan minat mereka melalui kegiatan yang secara khusus diselenggarakan oleh sekolah.”(Depdiknas RI 2008)

Kegiatan ini ada pada setiap jenjang pendidikan dari sekolah dasar hingga universitas. "Penyajiannya ditujukan agar siswa dapat mengembangkan kepribadian, bakat, dan kemampuannya di berbagai bidang di luar bidang akademik. Mereka juga bisa memperluas pengetahuan siswa, mengenai hubungan antar mata pelajaran, menyalurkan bakat dan minat, serta melengkapi pembinaan manusia seutuhnya di luar jam pelajaran sekolah."

Diantara prinsip-prinsip pembelajaran yang dapat digunakan dalam membuat perencanaan, pelaksanaan proses pembelajaran dan evaluasi pembelajaran adalah prinsip pembelajaran kontekstual (Contextual Teaching and Learning) (Kemendiknas RI 2011). Konsepnya mengkaitkan materi pelajaran dengan kehidupan nyata untuk memotivasi siswa membuat hubungan antara pengetahuan yang dipelajarinya dengan kehidupan mereka. Mereka selalu diberi kesempatan yang luas untuk bertanya dan berdiskusi agar dampak belajar bisa dirasakan (Bowo 2015; Hermawan 2016)

Kemendiknas RI (2011) telah menguraikan Sejumlah prinsip belajar CTL. 1) konstruktivisme adalah teori belajar yang menyatakan bahwa orang 
menyusun atau membangun pemahaman mereka dari pengalam-pengalaman baru berdasarkan pengetahuan awal dan kepercayaan mereka. Penerapan teori belajar konstruktivisme dalam pembelajaran dapat mengembangkan berbagai karakter, antara lain: berpikir kritis dan logis, mandiri, cinta ilmu, rasa ingin tahu, menghargai orang lain, betanggungjawab, dan percaya diri. 2) Penggunaan pertanyaan untuk menuntun berpikir siswa lebih baik daripada sekedar memberi siswa informasi untuk memperdalam pemahaman siswa. Pembelajaran yang menggunakan pertanyaan-pertanyaan untuk menuntun siswa mencapai tujuan belajar dapat mengembangkan karakter; berpikir logis dan kritis, rasa ingin tahu, menghargai orang lain, santun dan percaya diri.3) inkuiri dengan proses perpindahan dari pengamatan menjadi pemahaman, yang diawali dengan pengamatan dari pertanyaan yang muncul. Dalam pembelajaran berdasar inkuiri, siswa belajar berpikir kritis merumuskan masalah, mengamati, menganalisa, menyajikan atau melaporkan hasil analisanya. Pembelajaran yang menerapkan inkuiri dapat mengembangkan karakter berfikir kritis logis, kreatif, rasa ingin tahu, menghargai orang lain jujur, santun, tanggungjawab. 4) Masyarakat belajar dimana sekelompok siswa yang terikat dalam kegiatan belajar agar terjadi proses belajar lebih dalam (belajar bersama di dalam kelompok). Penerapan prinsip masyakat belajar di dalam proses pembelajaran dapat mengembangkan karakter, kerjasama, menghargai orang lain, santun, demokratis, patuh aturan sosial, tanggungjawab. 5) Pemodelan, adalah proses penampilan suatu contoh agar orang lain berpikir, bekerja, dan belajar. Pemodelan dalam pembelajaran dapat menumbuhkan karakter rasa ingin tahu, menghargai orang lain, percaya diri. 6) Releksi, yaitu cara berpikir tentang apa yang telah siswa pelajari dan untuk membantu siswa menggambarkan makna personal siswa sendiri. Di dalam refleksi, siswa menelaah kejadian, kegiatan, dan pengalaman serta berpikir tentang apa yang telah dipelajari dan bagaimana menggunakan oengetahuan baru tersebut. Refleksi dalam pembelajaran dapat mengembangkan karakter berpikir logis dan kritis, menghargai orang lain dan percaya diri.7) Penilaian Autentik, penilaian autentik sesungguhnya adalah suatu istilah yang diciptakan untuk menjelaskan berbagai metode penilaian 
alternatif. Penilaian autentik dalam pembelajaran dapat mengembangkan karakter kejujuran, tanggungjawab, menghargai orang lain, disiplin, cinta ilmu.

Selanjutnya prinsip kegiatan pembinaan kesiswaan meliputi, Individual, yang menyesuaikan sesuai dengan potensi, bakat dan minat siswa. Opsi atau Pilihan bagi siswa sehigga berasal dari keinginan sukarela dari diri sendiri bukan paksaan. Siswa terlibat aktif secara penuh. Pembelajaran dilakukan dalam suasana yang menyenangkan dan disukai oleh peserta didik. prinsip pembangunan semangat dari siswa guna membangun etos kerja. Kegiatan yang dilaksanakan memilliki kemanfatan bagi orang banyak Kemendiknas RI (2011).

Pada sekolah dasar yang berafiliasi denga organisasi keagamaan masyarakat Muhammadiyyah ada pendidikan Ekstrakurikuer Hizbul Wathan (HW). Gerakan kepanduan ini mendukung Muhammadiyah sebagai "gerakan Islam dakwah amar makruf nahi munkar dan tajdid, bersumber pada al quran dan sunnah yang didirikan oleh $\mathrm{KH}$ Ahmad Dahlan pada 8 Dzulhijjah 1330 H bertepatan dengan 18 November 1912 M di Yogyakarta, berasas Islam."(PP Muhammadiyah 2016).

Apabila pendidikan nasional mengenal Praja Muda Karana atau Pramuka, maka HW adalah Gerakan Kepanduan dalam Muhammadiyah. Sistem pendidikan di luar keluarga dan sekolah untuk anak, remaja dan pemuda itu dilakukan di alam terbuka dengan metode yang menyenangkan dan menantang, dalam rangka membentuk warga negara yang berguna dan mandiri (Kwartir Pusat HW 2007a:2).

Gerakan HW sangat berarti dalam pendidikan nasional Indonesia seperti Pramuka. Walaupun begitu, kegiatan yang pertama ada kekhasan tersendiri dari pada gerakan kepanduan terakhir. Zulfaturrohmawati (2017) telah menunjukkan kekhasan tersebut.

Pramuka menggunakan sistem tim, kemitraan anggota dewasa dalam kegiatan dan sistem unit terpisah, dan pembina memberikan teladan kepada anggota Pramuka. HW cenderung menekankan pada amalan aqidah Islam, pembinaan dan pembinaan akhlak mulia sesuai ajaran Islam. Adapun Persamaan keduanya tamapak pada; (1) aspek tujuan untuk 
menanamkan nilai karakter positif, (2) pembiasaan dan pengamalan, pemberian keteladanan, terciptanya lingkungan karakter yang menyenangkan (3) ) internalisasi nilai-nilai positif yang ditanamkan oleh seluruh warga sekolah. Sedangkan perbedaannya adalah (1) kode kehormatan pramuka adalah dasa darma, sedangkan HW adalah hukum pramuka, (2) pramuka bersifat universal, sedangkan HW bersifat nasional, dan (3) kepramukaan mengisi pengetahuan, stabilitas mental, keterampilan, pengalaman, perasaan sosial, spiritual, dan emosional, sedangkan HW tentang agama Islam dan keterampilan kepanduan.

HW telah berdiri sejak era sebelum kemerdekaan di Yogyakarta, tepatnya pada tahun $1918 \mathrm{M}(1336 \mathrm{H})$. setelah beberapa lama vakum, kemudian dibangkitkan kembali pada tanggal 10 Sya'ban $1420 \mathrm{H}$ bertepatan dengan tanggal 18 November 1999 M oleh Pimpinan Pusat Muhammadiyah dengan surat keputusan nomor 92/SK-PP/VI-B?1.b/1999 tanggal 10 Sya'ban $1420 \mathrm{H} / 18$ November $1999 \mathrm{M}$ dan dipertegas dengan surat keputusan Pimpinan Pusat Muhammadiyah nomor 10/Kep/I.O/B/2003 tanggal 1 Dzulhijjah 1423 H / 2 Februari 2003 M untuk waktu yang tidak ditentukan. Untuk tingkat pendidikan Dasar berada pada Athfal; yaitu anggota HW yang berusia antara 6-11 tahun. Selama pembelajaran, masing- masing peserta memiliki panggilan khusus. Ramanda/Ibunda; panggilan untuk pembina, pembantu pembina dan pelatih golongan Athfal. Panggilan itu juga biasa disebutkan untuk panggilan sesama pembina/pelatih. Rakanda/Ayunda; panggilan untuk pembina, pembantu pembina golongan pengenal, penghela dan penuntun. Rimata; panggilan untuk pemimpin kerabat atau pembantu pembina golongan penghela. Rais; panggilan untuk pemimpin kafilah atau pembantu pembina golongan penuntun. Auladi; panggilan untuk anggota HW golongan Athfal (Kwartir Pusat HW 2007a, n.d.).

Peserta HW berada tingkat Athfal ada janji dan Undang-undang tersendiri. Janjinya sebagai berikut;

Mengingat harga perkataan saya, maka saya benjanji dengan sungguh-sungguh: Satu, setia mengerjakan kewajiban saya terhadap Allah. Dua, selalu menurut Undang-undang Athfal dan setiap hari berbuat kebajikan (Kwartir Pusat HW 2007a). 
Undang-undang Athfal berisi; "Satu, Athfal itu selalu setia dan berbakti pada ayah dan bunda. Dua, Athfal itu selalu berani dan teguh hati" (Kwartir Pusat HW 2007a).

Salah satu gerakan kepanduan yang setingkat dengan pramuka tingkat siaga itu sangat berperan dalam pendidikan karakter di Indonesia. Kusumawati (2012) pembentukannya terjadi melalui pembekalan adik-adik siaga dengan nilai dan ketrampilan bermuatan ilmu pengetahuan dan teknologi yang berkembang. Ajirna dkk (2018) menemukan dalam penelitian kualitatif di SDN 20 Banda Aceh bahwa pembentukan karakter siswa terjadi melalui pembiasaan, pemberian contoh teladan, penugasan dan nasehatnasehat dari kakak pembina. Yuliani, Halimah, dan Bakhraeni (2016) menggunakan angket dan observasi untuk meyimpulkan bahwa pembina telah merencanakan kegiatan pramuka dengan mengutamakan penumbuhan karakter disiplin dan peduli lingkungan sehingga keduanya menyetujuinya sebagai alternatif dalam pendidikan karakter. Di SDN 1 Parungkamal (Yuliyani 2018) ditemukan pramuka memprioritaskan pada berbagai kegiatan dan keterampilan daripada teori yang dapat membangun kepribadian dan kecakapan hidup yang sesuai dengan kode kehormatan; Dasa Dharma dan Satya Pramuka. Penanaman karakter kemandirian pun telah diteliti oleh Larasati (2017). Ia mengemukakan dalam penelitiannya di SDIT AlMuhajirin bahwa;

Nilai karakter kemandirian yang ditanamkan adalah sikap disiplin, tidak berganantung pada orang lain, keberanian, kepercayaan diri, solutif dan mampu mengambil keputusan, dan bertanggung jawab. Kegiatan ekstrakurikuler Pramuka dalam mewujudkan pendidikan karakter mandiri pada siswa dilakukan melalui; latihan rutin, perkemahan, Lomba Tingkat, dan jambore. Strategi yang digunakan adalah strategi pemanduan (cheerleading), strategi pujian dan hadiah (praiseand-reward), strategi definisikan dan latihkan (define-and-drill) dan strategi penegakan disiplin (forced formality). Dalam hal ini sudah sampai pada tahap moral doing tetapi belum tercapai secara maksimal karena tidak semua siswa mempraktikkan nilai karakter mandiri itu di dalam perilakunya sehari-hari. Faktor pendukungnya berupa keingian dan kesadaran dari diri siswa, serta adanya support dari wali kelas, guru dan orang tua. Selanjutnya faktor penghambat muncul diri siswa sendiri yang 
terbiasa dengan kebiasaan buruk serta pengaruh buruk dari kondisi perlakuan orang tua dan lingkungan sekitar seperti teman sebaya dan lain-lain (Larasati 2017).

HW pun berarti dalam pendidikan karakter bangsa Indonesia tingkat dasar meski ada kendala dan hambatan yang harus dijalani. Efendi ( 2018) menyimpulkan kegiatan HW di Sekolah Dasar Muhammadiyah 6 Palembang dalam penanaman karakter kepemimpinan belum optimal meski telah diusahakan sepenuhnya oleh para pembina yang terbatas selain kekurangan dalam minat dan motivasi siswa.

Penelitian ini bertujuan untuk mendeskripsikan pendidikan kemandirian melalui kegiatan $\mathrm{HW}$ tingkat athfal di salah satu SD Muhammadiyah di Yogyakarta. Ekstrakurikuler itu dilaksanakan di SD Muhammadiyah Serut yang beralamat di Dusun Serut, RT 03 Desa Palbapang Kecamatan Bantul Kabupaten Bantul DIY. Dalam Penanaman karakter mandiri tentu khas dari Pramuka apabila merujuk bahwa keduanya memiliki perbedaan dan persamaan dalam kepanduan. Relasi Pembina dan perserta siaga ibarat relasi pendidik dan peserta didik yang merujuk pada Quran sebagai pedoman pokok Islam sebagai fokus utama dalam HW. keunikannya telah diuraikan oleh Fatihah dan Nadjih (2017). Materi Islam dan Kemuhamadiyahan yang diajarkan dalam kelas (Huda dan 'Aisyah 2018) tentu juga disampaikan selama kegiatan HW di luar kelas.

\section{Metode Penelitian}

Arikunto menyebut penelitian lapangan sebagai,"Penelitian yang dilakukan di luar laboratorium"(Arikunto 2017:11) Penelitian ini juga tidak sesuai kategori penelitian tindakan kelas yang diajukan oleh Prihantoro dan Hidayat karena tidak ada internvensi di dalamnya, namun berupaya mengumpulkan data untuk dideskrispsikan secara natural apa yang terjadi di lapangan dan di analisis secara kualitatif. Penelitian lapangan merupakan penelitian yang dilakukan dengan mengumpulkan data dan informasi yang diperoleh langsung dari responden dengan mengamati secara langsung pelaksanaan ekstrakurikuler HW tingkat Athfal di SD Muhammadiyah Serut. Selama observasi diharapkan memberikan kemudahan dalam pengumpulan 
data langsung bagaimana proses pendidikan kemandirian melalui ekstra kurikuler HW yang dijalankan. Di situlah pengamatan dan pencatatan secara langsung dan sistematis terhadap gejala yang tampak pada obyek yang diteliti."(Margono 2014:158) Wawancara mendalam digunakan untuk melihat pandangan dan pemahaman lebih dalam bagaiamana ekstra HW berjalan di tingkat dasar. Informan utama adalah Kepala Sekolah dan para kakak Pembina HW terutama tentang Informasi yang akan digali dari pembina HW adalah tentang materi, pelaksanaan dan hasil yang dicapai ekstrakurkuler HW di SD Muhammadiyah Serut. Penggalaian data melalui dokumnetasi juga dilakukan dengan cara Pada penelitian ini dokumendokumen yang penulis teliti antara lain, data sekolah, data dinding, data pelaksanaan $\mathrm{HW}$, data penilaian, dokumentasi kegiatan berupa foto ekstrakurikuler HW SD Muhammadiyah Serut Bantul. Data kemudian dianalisis secara non statistik yang bersifat kualitatif. Dalam hal ini penelitian kualitatif mengajak seseorang untuk mempelajari sesuatu masalah yang ingin diteliti secara mendasar dan mendalam. Data yang ditemukan adalah satu pedoman yang langsung terdapat pada apa yang dicari (Margono 2014:190).

\section{Hasil dan Pembahasan}

Pelajar peserta HW di SD Muhammadiyah Serut tidak ditujukan untuk semua kelas. Peserta ekstrakurikuler HW SD Muhammadiyah adalah siswa kelas 3, 4 dan 5. Pembinanya terbagi menjadi dua, dari dalam sekolah yang terdiri dari para guru dan dari luar dengan mengundang para Pembina aktivis HW dari luar lingkungan SD. Pelaksanaannya pada setiap hari Sabtu, jam 11.00-13.00 WIB. Secara umum tahapan pelaksanaan HW SD Muhammadiyah Serut, adalah sebagai berikut: 1) Apel pembukaan, 2) Materi, 3) Sholat Dhuhur, 4) Materi, 5) Apel penutup

Materi yang diajarkan atau yang diberikan oleh pelatih kepada peserta didik dalam ekstrakurikuler HW di SD Muhammadiyah Serut merujuk materi yang terdapat dalam kurikulum HW yang diterbitkan oleh Kwartir Pusat HW, dengan mempertimbangkan kesesuaian situasi dan kondisi SD Muhammadiyah Serut. 
Berdasarkan kurikulum Gerakan Kepanduan HW, materi yang disampaikan kepada Pandu Athfal adalah sebagai berikut: 1) Salam Athfal, 2) Seruan Rumpun Pembukaan dan Penutupan, 3) Lagu Indonesia Raya, 4) Mars HW, 4)Kalimat Syahadat, 5) Rukun Iman dan Rukun Islam, 6) Doa sehari-hari, 7) Arti Muhammadiyah dan pendiri, 8) Undang-undang HW dan Athfal, 9) Cara berpakaian, 10) Simpul mati, Jangkar dan Pangkal, 11) Membaca Jam, 12) Budi pekerti, 13) Adzan iqamah dan sholat, 14) Membersihkan alat rumah tangga (piring, alumunium, d1l), 15) Menabung, 16) Kebersihan diri dan lingkungan, 17) Arah mata angin, 18) Ortom Muhammadiyah, 19) Sholat berjamaah, 20) Hafalan Surat-surat Juz 'Amma, 21) PPPK, 22) Hasta Karya, 23) Menyalakan api, 24) Mendirikan tenda, 25) Morse dan semapor, 26) Materi lain sesuai dengan situasi dan kondisi (Kwartir Pusat HW 2007b:13).

Materi yang ada dapat dikelompokkan menjadi empat bagian, Kepanduan, Ke-Islaman, Kemuhammadiyahan dan Kecakapan praktis. Materi Kepanduan terdiri dari; Salam Athfal, Seruan Rumpun, Lagu Kebangsaan, Mars HW, Janji Athfal, Undang-Undang Athfal, Janji dan Undang-undang HW, Morse dan Semapor, Pendirian Tenda. Materi Undang-undang HW dominan bidang akhlaq, baik akhlak terhadap diri sendiri, kepada orang tua. orang lain, lingkungan, bangsa dan negara. Melalui materi Undang-undang HW diajarkan kepada para Pandu agar tertanam sikap dalam dirnya amanah (dapat dipercaya), cinta perdamaian, setia, taat aturan, menghormati pemimpin, sabar dan pemaaf, hemat cermat, sayang terhadap semua makhluk, suci pikiran perkataan dan perbuatan.

Materi Al-Islam bermuatan antara lain; Rukun Iman, Rukun Islam, Syahadat, Adzan, Iqomah, Sholat, Sholat Berjamaah, Doa harian, Hafalan surat-surat pendek (Juz 'Amma). Dari ragam materi yang ditetapkan untuk disampaikan pada tingkat Athfal nampak sangat kuat muatan Pendidikan Agama Islam. memuat pendidikan agama Islam dalam bidang ibadah. Materi ini sangat penting untuk dikuasai oleh peserta agar mereka memiliki pengetahuan yang benar terhadap tatacara pelaksanaan ibadah dalam agama 
Islam dan terbiasa mengamalkan praktik ibadah yang benar menurut ajaran Islam sejak dini.

Materi Kemuhammadiyahan menjadi penciri dari HW sebagai bagian dari Muhammadiyah. Yang termasuk materi Kemuhammadiyahan berdasar materi yang diberikan dalam Pandu Athfal antara lain; Arti Muhammadiyah, Pendiri Muhammadiyah, ORTOM Muhammadiyah, lagu-lagu ORTOM Muhammadiyah antara lain Mars 'Aisyiyah, Mars Nasyiatul 'Aisyiyah, Mars IPM.

Materi Kecakapan Praktis. Kecakapan praktis yang dimaksud dalam materi ini adalah segala kecakapan atau keterampilan dalam menyelesaikan suatu pekerjaan tertentu yang berkaitan langsung dengan aktivitas kehidupan sehari-hari. Yang masuk materi kecakapan praktis antara lain; tali temali, membaca jam, arah mata angin, kebersihan diri dan lingkungan, membersihkan alat-alat rumah tangga, menabung, PPPK, menyalakan api, budi pekerti. Dengan menguasai materi kecakapan praktis ini diharapkan para Pandu (peserta didik $\mathrm{HW}$ ) dapat mandiri dalam menyelesaikan keperluannya tidak tergantung terhadap orang lain.

Metode yang digunakan oleh para pelatih (pembina) dalam pelaksanaan latihan HW di SD Muhammadiyah Serut antara lain; metode ceramah, metode diskusi, metode kerja kelompok, dan metode demonstrasi. Selain metode tersebut kadang juga dengan metode permainan atau game. Masingmasing metode digunakan sesuai dengan materi yang diajarkan ketika latihan dan dalam rangka membangun suasana yang menggembirakan dalam pelaksanaan latihan HW.

Metode ceramah digunakan untuk materi Kemuhammadiyahan, Syahadat, Fiqih Puasa, Budi Pekerti. Metode diskusi dan kerja kelompok digunakan untuk menyampaikan materi Budi Pekerti, Yel-Yel, membuat tandu, membersihkan lingkungan dan lain-lain. Metode demonstrasi digunakan untuk materi sandi morse, pendirian tenda, PPPK, adzan, iqamah, sholat, hafalan doa-doa, hafalan surat-surat pendek (Juz 'Amma).

Setelah kegiatan belajar mengajar berakhir pada pukul 11.00 selanjutnya dilaksanakan kegiatan $\mathrm{HW}$. Siswa kelas 3,4 dan 5 
mempersiapkan diri di halaman sekolah, mengenakan baju seragam $\mathrm{HW}$, siswa putri mengenakan baju seragam lengkap dengan jilbab dan celana panjang menutup aurat dan kelengkapan seragam lainnya seperti hasduk warna hijau (hasduk HW) dan topi HW berwarna Hijau, begitu pula siswa putera juga mengenakan seragam HW dengan celana panjang menutup aurat lengkap dengan hasduk HW dan topi hijau beserta perlengkapan tongkat $\mathrm{HW}$ dan tali. Dengan penuh semangat dan riang mereka mempersiapkan diri berbaris rapi di halaman sekolah untuk memulai apel pembukaan HW hari itu.

Jalannya apel pembukaan adalah: Pembina (Pelatih) menyiapkan para siswa dengan memberi aba-aba peluit sebagai tanda kumpul, kemudian pembina memberi aba-aba untuk menyusun barisan dengan rapi, setelah rapi pembina mengucapkan salam pembuka, kemudian dilanjutkan dengan doa akan belajar dibaca secara bersama, setelah itu pengarahan singkat dari pembina yang berisi antara lain materi yang akan dipelajari hari itu. Selanjutnya peserta dipisahkan sesuai dengan tingkat kelas masing-masing, dengan dipandu pembina masing-masing. Untuk siswa kelas 5 dipandu oleh Kak Ari Wahyu Diananto.

Materi untuk kelas 5 di saat observasi adalah latihan mendirikan kerangka tenda kemah. Sebelumnya dilakukan presensi kehadiran siswa oleh pembina, selanjutnnya penyampaian materi, pertama peserta dibagi menjadi beberapa kelompok, setelah terbagi menjadi beberapa kelompok kemudian pembina mendemonstrasikan cara mendirikan tenda dengan menggunakan tongkat dan tali. Alat yang digunakan tongkat, tali dan patok. Metode yang digunakan oleh pembina untuk menyampaikan materi latihan mendirikan tenda adalah metode demonstrasi, yakni pembina memberikan contoh bagaimana mendirikan dua tongkat dengan jarak tertentu kemudian tongkat tersebut diikat dengan kuat dan dihubungkan dengan tali yang sudah disiapkan sehingga kedua tongkat berfungsi sebagai tiang penyangga tenda yang akan dipasang, setelah tongkat diikat dengan tali, kemudian tali ditarik kesamping kanan, kiri, dan depan atau belakang kemudian diikat pada patok yang ditancapkan di tanah. Setelah jelas cara mendirikan rangka tenda 
dengan menggunakan tongkat, tali dan patok, kemudian para siswa mempraktikkan cara mendirikan tenda dengan menggunakan tongkat, tali dan patok secara kelompok.

Sholat dhuhur berjamaah, setelah sholat dhuhur berjamaah dilanjutkan materi dan apel penutup. Pada apel penutup, secara bersamasama seluruh peserta melakukan tepuk HW secara bersama dengan penuh semangat, kemudian membaca doa penutup secara bersama-sama, doa yang dibaca adalah (Allahumma arinal haqqa haqqa warzuqnattiba'ah wa arinal bathila bathila warzuqnaj tinabah), tepuk $\mathrm{HW}$ dan diakhiri salam dan jabat tangan dengan mencium tangan pembina (pelatih) oleh siswa kepada pembina, kemudian pulang.

Pada salah satu observasi materi yang disampaikan adalah tentang Puasa Ramadhan, menyongsong bulan Ramadhan yang sebentar lagi datang. Tahapan pelaksanaan latihan sama dengan sebelumnya. Pertama pembina meniup peluit tanda peserta kumpul, kemudian peserta berbaris rapi siap mengikuti apel pembuka, kemudian pembina membuka kegiatan latihan dengan berdoa bersama, menyampaikan amanat singkat kemudian apel pembuka selesai dilanjutkan penyampaian materi. Kali ini metode yang digunakan pembina adalah metode ceramah, peserta duduk dihalaman mengambil tempat yang teduh, peserta menyimak materi yang disampaikan oleh pembina tentang puasa Ramadhan, diselingi aneka macam tepuk seperti; tepuk satu, tepuk anak sholeh, tepuk sukses, tepuk senyum sehingga suasana ceria. Selanjutnya sholat duhur berjamaah, setelah selesai dilanjutkan kerja bakti di lingkungan sekolah dan sekitar sekolah, kemudian apel penutupan.

Dari sisi materi, focus pada pendidikan kemandirian sebagai bagian dari pengembangan karakter bangsa dalam HW di Serut seperti gerakan HW dan kepramukaan lainnya (Efendi 2018; Kusumawati 2012; Yuliyani 2018; Zulfaturrohmawati 2017). seperti yang sesuai pendidikan nasional Pemberian bimbingan keislaman dan kemuhammadiyahan di $\mathrm{HW}$ juga terdapat dalam pelajaran dalam kelas(Efendi 2018; Huda dan 'Aisyah 2018). Hal demikian semakin memperjelas bahwa ada relasi pendidikan intra dan ekstra kurikuler. HW menjadi sarana untuk pendalaman materi pelajaran yang ada pada 
intrakurikuler dalam kelas melalui kontekstualisasinya dalam kehidupan pendidikan ekstrakurikuler dalam kelas. Caranya bisa berbagai macam, demonstrasi hafalan di depan teman siaga, diskusi panjang lebar, atau pembina menunjukkan dalam kehidupan sebenarnya meski masih dalam kerangka pendidikan. Pengajaran materi yang kontekstual menjadi pokok dalam kegiatan HW. Hal demikian sesuai dengan yang dipedomani oleh Kemendiknas RI (2011)

\section{Penutup}

Dengan materi dan metode pelaksanaan kegiatan yang ada Pendidikan kemandirian dalam kegiatan Ekstrakurikuler HW di SD Muhammadiyah Serut telah selaras dengan UU No. 20 tahun 2003 Tentang Sistem Pendidikan Nasional bahwa fungsi pendidikan untuk mengembangkan kekuatan spiritual keagamaan, pengendalian diri, kepribadian, kecerdasan, akhlak mulia, serta keterampilan yang diperlukan peserta didik, masyarakat, bangsa dan negara.

Saran kepada tim pembina perlu mengembangkan materi yang telah ditetapkan oleh Kwartir Pusat HW, terutama materi pengenalan para tokoh muslim nasional, sehingga tumbuh semangat siswa untuk meneladani semangat perjuangannya dalam mengamalkan dan mendakwahkan Islam serta berkontribusi dalam pembangunan bangsa dan negara. Tim pembina juga perlu menyusun silabus dan rencana program pembelajaran agar pelaksanaan ekstrakurikuler HW lebih terarah dan terukur.

\section{Referensi}

Ajirna, Ajirna, M. Nasir Yusuf, dan Hasmiana Hasan. 2018. "Upaya Pembentukan Karakter Siswa Melalui Kegiatan Pramuka Di SD Negeri 20 Banda Aceh." Jurnal Ilmiah Mahasiswa Pendidikan Guru Sekolah Dasar 3(3):46-52.

Arikunto, Suharsimi. 2017. Prosedur Penelitian Suatu Pendekatan Praktik. Jakarta: Rineka Cipta.

Bowo, Ahmad Nasir Ari. 2015. Cerita Cinta Belajar Mengajar. Yogyakarta: Deepublish.

Depdiknas RI. 2008. Kamus Besar Bahasa Indonesia Pusat Bahasa. Jakarta: PT Gramedia Pustaka Utama.

Efendi, Musni. 2018. "Penerapan Pendidikan Karakter Melalui Program Gerakan Kepanduan Hizbul Wathan Pada Sekolah Dasar Muhammadiyah VI Palembang." Conciencia 17(1):27-39. 
Fatihah, Nurul, dan Difla Nadjih. 2017. "Hubungan Pendidik Dan Terdidik Dalam Al-Quran." Ulumuddin: Jurnal Ilmu-ilmu Keislaman 7(2):73-86.

Hermawan, Toto. 2016. "Pengaruh Kemampuan Bertanya Terhadap Hasil Belajar." Intersections 1(1).

Huda, Lukman Nur, dan Siti 'Aisyah. 2018. "Pembelajaran Mata Pelajaran Al-Islam Di SD Muhammadiyah Mrisi Kabupaten Bantul." Ulumuddin: Jurnal Ilmu-ilmu Keislaman 8(1):1-16.

Junaedi, Rusli Akhmad. 2018. "Model Pendidikan Kepramukaan Indonesia dalam Perspektif Filsafat Pendidikan Paulo Freire." Jurnal Filsafat 28(2):220-52.

Kemendiknas RI. 2011. Panduan Pendidikan Karakter Di Sekolah Menengah. Jakarta: Kemendiknas RI.

Kusumawati, Intan. 2012. "Pembentukan Karakter Siswa Melalui Pendidikan Kepramukaan." Academy of Education Journal 3(1):75-91.

Kwartir Pusat HW. 2007a. Anggaran Dasar dan Anggaran Rumah Tangga Gerakan Kepanduan Hizbul Waton. Yogyakarta: Suara Muhammadiyah.

Kwartir Pusat HW. 2007b. Kurikulum Gerakan Kepanduan HW. Yogyakarta: Suara Muhammadiyah.

Kwartir Pusat HW. n.d. "Kebangkitan HW dan Sejarah Kepanduan di Indonesia." Diambil (https://hizbulwathan.or.id/kebangkitan-hw-dansejarah-kepanduan-di-indonesia/).

Larasati, Eki Dwi. 2017. "Pendidikan Karakter Mandiri Melalui Kegiatan Ekstra kurikuler Pramuka Di Sekolah Dasar." 6(5):381-88.

Margono, S. 2014. Metodologi Penelitian Pendidikan. Jakarta: Rineka Cipta.

PP Muhammadiyah. 2016. Anggaran Dasar dan Anggaran Rumah Tangga. Yogyakarta: Suara Muhammadiyah.

RI. 2003. Undang-undang Republik Indonesia Nomor 20 Tahun 2003 Tentang Sistem Pendidikan Nasional.

RI. 2010. Peraturan Pemerintah Republik Indonesia Nomor 17 Tahun 2010 Tentang Pengelolaan dan Penyelenggaraan Pendidikan.

Sarumaha, Yenny Anggreini. 2016. "Perubahan Pembelajaran Yang Berpusat Pada Guru Ke Berpusat Pada Siswa." Intersections 1(1).

Yuliani, Rini, Momoh Halimah, dan Reni Bakhraeni. 2016. "Pengembangan Pendidikan Karakter Melalui Gerakan Pramuka (Studi Kasus Kegiatan Kepramukaan Di SD Negeri Citapen Kecamatan Tawang Kota Tasikmalaya Tahun 2015/2016)." PEDADIDAKTIKA: Jurnal Ilmiah Pendidikan Guru Sekolah Dasar 3(2):238-47.

Yuliyani, Devy Riri. 2018. "Membangun Karakter Siswa Melalui Kegiatan Kepramukaan di SD Negeri 1 Parungkamal." Jurnal PANCAR 2(2).

Zulfaturrohmawati, Ana. 2017. "Implementation of character education in Dasa Darma of Scouts and Hizbulwathan Boys Scout Laws." Attarbiyah: Journal of Islamic Culture and Education 2(2):257. 
Wiranthi Prastomo, Nuhiyatul Huliyah, II. Nasrudin, Intan Kusumawati, Nuryati, A.N. Aribowo 